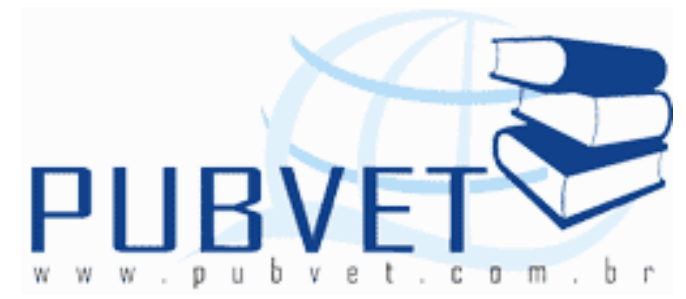

PUBVET, Publicações em Medicina Veterinária e Zootecnia.

\title{
Perosomus Elumbis em Bovino - Relato de Caso
}

Caio Rodrigues dos Santos, Priscila Sarkozi Pereira da Silva, Kátia Pimenta Guimarães e Guilherme Durante Cruz

Departamento de Patologia, Faculdade de Medicina Veterinária, Universidade de Santo Amaro.

\section{Resumo}

Este artigo descreve um caso de Perosomus Elumbis em um bovino. $O$ animal foi encaminhado já em óbito ao Hospital Veterinário da Universidade de Santo Amaro, São Paulo, Brasil, em maio de 2013. Ao exame radiológico revelou a anomalia morfológica presente no eixo vertebral. Já na análise necroscópica, foi observado agenesia do eixo vertebral na região lombar e sacral e várias deformidades ósseas nas vértebras torácicas.

Palavras Chave: Má formação, Bovinos, Perosomus.

\begin{abstract}
This paper describes a case of Perosomus Elumbis in female calf. The animal was present dead to Santo Amaro University Veterinary Hospital, São Paulo, Brazil in May 2013. Radiologic examination revealed the presence morphological anomaly in vertebral axis. Necropsy examination revealed agenesis of vertebral axis in lumbar and sacral region, several deformity in thoracic vertebral was seem too.
\end{abstract}

Keywords: Deformity, Calf, Perosomus 
SANTOS, C.R. et al. Perosomus Elumbis em Bovino - Relato de Caso. PUBVET, Londrina, V. 7, N. 23, Ed. 246, Art. 1626, Dezembro, 2013.

\section{Relato de Caso:}

Perossomus Elumbis é uma rara anomalia congênita, na qual sua etiologia ainda é desconhecida. Esta anomalia é representada pela deformidade da região pélvica de fetos, principalmente de bovinos. Nesses casos o segmento lombar e sacral da medula espinal estão ausentes, concomitantemente a essa anomalia, o animal acometido pode desenvolver uma atrofia muscular na região pélvica e artrogripose, caracterizado por uma anquilose das articulações $(4,5)$. O primeiro relato de Perossomus Elumbis na Medicina Veterinária foi em 1832 quando o Anatomista e Patologista Ernst Gurlt escreveu um livro sobre más formações em animais domésticos (4). Após esta data houve relatos de Perosomus Elumbis em suínos (1) ovinos, caprinos e cachorros (2). A etiologia ainda não esta bem esclarecida, sendo que sua incidência representa menos de $1 \%$ dentro das más formações congênitas observadas na Medicina Veterinária (3).

Defeitos Congênitos podem ser resultantes de eventos em um ou mais estágios do complexo de transição do embrião para o desenvolvimento fetal (4.) Más formações ou uma inadequada migração do tubo neural durante o desenvolvimento caudal do embrião, pode ser umas das possíveis causas desta anomalia (3). Hiraga et al. cita a possibilidade do não fechamento do tubo neural em sua porção central, o que pode resultar em más formações. A ingestão da planta Veratrum californicum, também é considerada uma possível etiologia para esta má formação (6).

Um animal da espécie bovina e da raça holandesa foi encaminhado ao Hospital Veterinário da Universidade de Santo Amaro já em óbito. Foi realizado exame radiológico, onde se observou alteração morfológica de corpos vertebrais torácicos, com modificação do eixo da coluna vertebral, ausência das vértebras lombares, sacrais e coccígeas e deformidade torácica devido às alterações morfológicas das vértebras torácicas (Figura 01-A). Após exame radiológico, o animal foi encaminhado ao serviço de Anatomia Patológica para o exame necroscópico, onde foi constatado aborto pelo teste de docimasia 
SANTOS, C.R. et al. Perosomus Elumbis em Bovino - Relato de Caso. PUBVET, Londrina, V. 7, N. 23, Ed. 246, Art. 1626, Dezembro, 2013.

pulmonar positivo, agenesia de todos os segmentos vertebrais lombares e sacrais, deformidade das vértebras torácicas, disposição incorreta da medula espinal em região torácica e atrofia muscular na região pélvica (Figura 01-B).
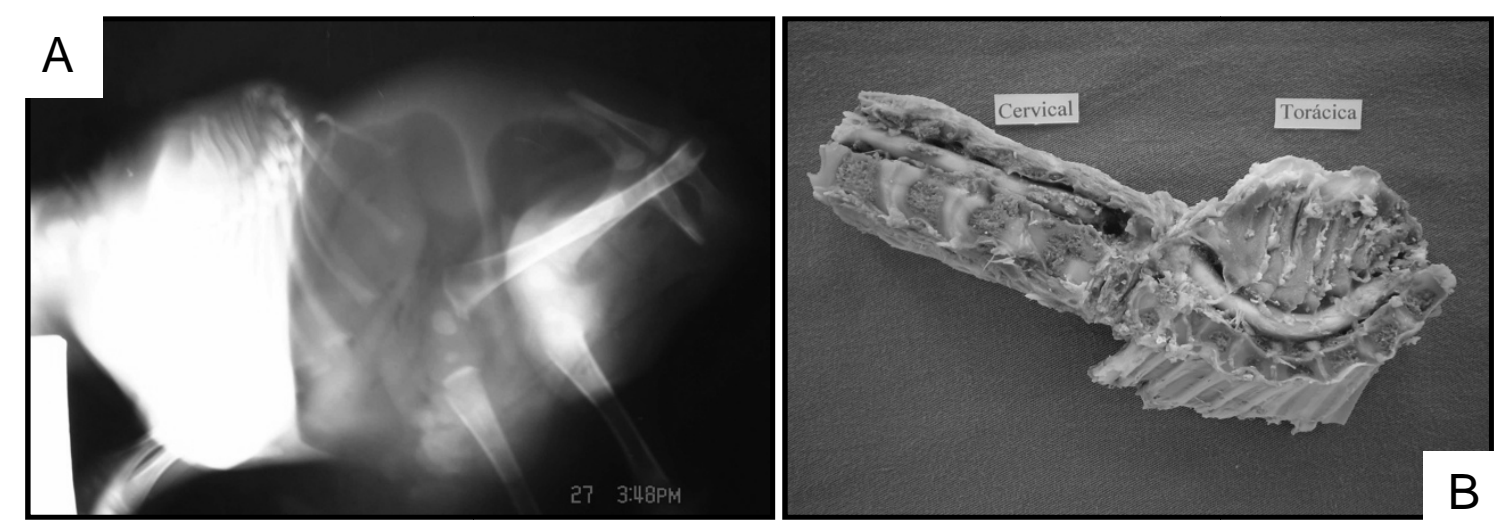

Figura 1: (A) Observa-se a modificação do eixo da coluna vertebral e agenesia de vértebras lombares e sacrais (B) Observa-se a deformidade da coluna vertebral em região torácica, com o comprometimento da medula espinal.

Pode-se concluir que a incidência de Perosomus Elumbis em bovinos é muito baixa, no Brasil, ainda há poucos relatos desta anomalia envolvendo animais da espécie bovina. Muito recentemente houve um relato de Perosomus Elumbis (3) em um bezerro na cidade de Franca, região norte do Estado de São Paulo. Relatos envolvendo animais com esta anomalia na cidade de São Paulo ainda não foi relatada, tornando este um caso inédito na cidade, porém novos estudos epidemiológicos ainda precisam ser realizados, a fim de esclarecer as possíveis etiologias envolvidas.

\section{Agradecimentos:}

Ao Departamento de Patologia da Faculdade de Medicina Veterinária e Zootecnia da Universidade de São Paulo. 
SANTOS, C.R. et al. Perosomus Elumbis em Bovino - Relato de Caso. PUBVET, Londrina, V. 7, N. 23, Ed. 246, Art. 1626, Dezembro, 2013.

\section{Referências:}

1. AVEDILLO L. J., CAMÓN J. Perosomus Elumbis in a Pig, Veterinary Record 160, 127-129, 2007.

2. LEE Y., CHOI H., CHANG D., EOM K., YOON J., CHOI M., LEE K., YEON S., LEE H., WON C., LEEH. Perosomus Elumbis in a Korean Calf, Imaging Diagnosis 48(1), 30-31, 2007.

3. CASTRO M.B., SZABÓ M.P.S., HOKAMURA H.K., ROMANO M.A. Perosomus Elumbis in Hostein Calf Brazil, Veterinary Record152, 753, 2003.

4. JONES C.J.Perosomus Elumbis (Vertebral Agenesis and Arthrogryposis in a Stillborn Hostein Calf), Veterinary Pathology 36, 64-70, 1999.

5. HIRAGA T., ABE M. Anatomical Observation of Six Calves Affected with Segmental Aplasia of the Spinal Cord, Anatomical Record 219, 402-408, 1987.

6. DENNIS, S.M. Perosomus Elumbis in Sheep, Australian Veterinary Journal 51, 135-136, 1975. 